\title{
Synthesis of silver nanoparticles using bio valorization coffee waste extract: photocatalytic flow-rate performance, antibacterial activity, and electrochemical investigation
}

\author{
Nagwa El-Desouky ${ }^{1} \cdot$ Kamel Shoueir $^{1,2} \cdot$ Ibrahim El-Mehasseb $^{3} \cdot$ Maged El-Kemary $^{1}$ \\ Received: 1 September 2021 / Revised: 4 December 2021 / Accepted: 18 December 2021 \\ (c) The Author(s), under exclusive licence to Springer-Verlag GmbH Germany, part of Springer Nature 2022
}

\begin{abstract}
It is well known that biogenic synthesis, as compared to other processes, has proven to be highly effective in the fabrication of silver nanoparticles (AgNPs). Thus, our current study focused on synthesizing AgNPs using coffee waste extract (CWE). CWE contains many compounds identified by HPLC, which reduce, cap, and stabilize AgNPs in its solution. The as-synthesized AgNPs were produced with a monodispersed small size around $20 \mathrm{~nm}$ and exhibited in-plane dipole plasmon resonances of hexagonal nanoplates. AgNPs were characterized by both physical and spectroscopic methods, which confirmed their nanoscale dimensions with a hexagonal shape. The as-prepared AgNPs (12 mg) enabled the photodegradation of phenol compounds $(20 \mathrm{~mL})$ with a removal efficiency of $\sim 94.6 \%$ in a short time in the presence of citric acid. Additionally, the second promising application of AgNPs was the tendency to remove the hazard 2,4 dinitroaniline (2,4 DNA) with a percent more than $97 \%$ while using only $7 \mathrm{mg}$ of AgNPs. Moreover, the green synthesized AgNPs are superior in inhibiting bacterial growth and killing most infected microbes such as B. subtilis, P. aeruginosa, S. aureus, and E. coli. The electrochemical characteristics of the AgNPs were evaluated using a three-electrode system. The calculated specific capacitance was 280 $\mathrm{F} \mathrm{g}^{-1}$ at $0.56 \mathrm{~A} \mathrm{~g}^{-1}$. Furthermore, after 1000 cycles at $2.2 \mathrm{~A} \mathrm{~g}^{-1}$, the AgNPs electrode demonstrates an excellent cycling stability behavior with $94.8 \%$ capacitance retention. Based on the previous promising results, it can be concluded that CWE is an environmentally benign extract to prepare AgNPs with low cost, saving and easily used for many great domains in photocatalytic, phenol compound removals, and production of functional nanodevices.
\end{abstract}

Keywords Green synthesis of AgNPs $\cdot$ Coffee waste extract $\cdot$ HPLC $\cdot$ Photocatalytic activity $\cdot$ Antibacterial . Supercapacitance

\section{Introduction}

Organic and inorganic pollutants endanger human life by inducing many diseases in aquatic environments and human health, notably mutagenic, poisonous, teratogenic,

Kamel Shoueir

kamel_rezk@nano.kfs.edu.eg

Maged El-Kemary

elkemry@nano.kfs.edu.eg

1 Institute of Nanoscience \& Nanotechnology, Kafrelsheikh University, Kafrelsheikh 33516, Egypt

2 CNRS UMR 7515-Université de Strasbourg, 25 rue Becquerel, 67087 Strasbourg, France

3 Faculty of Science, Kafrelsheikh University, Kafrelsheikh 33516, Egypt and carcinogenic implications $[1,2]$. As a result, even at extremely low concentrations, impacts on numerous human health diseases such as kidney, brain, liver, reproductive system, central nervous system, and epigenetic modifications might arise. According to the US Environmental Protection Agency, phenolic chemicals are potential poisons, including nitrophenols, chlorophenols, and alkylphenols [3].

Phenolic compounds and nitro-organics are among the most dangerous organic contaminants. Pesticides, herbicides, textiles, pharmaceuticals, and detergents are all raw sources of toxins in water [3, 4]. Conventional treatment methods like sedimentation and flocculation, as an example, are insufficient to ensure good water quality [5]. Besides phenols, dinitroaniline and its isomers are released into the environment via industrial waste or as degradation products of herbicides, pesticides. They have been listed as priority pollutants in many countries. These compounds can undergo 
complex environmental transformations at trace levels after entering the environment, posing potential environmental hazards. Also, nausea, dizziness, and headache can be caused by acute or chronic nitroaniline exposure because of their widespread industrial use [6].

Due to their distinctive qualities, including specific shape, size, and surface area [7], silver nanoparticles (AgNPs) seems to have several unique characteristics, including surface plasmon resonance (SPR), electric conductivity, antimicrobial activity against a wide range of bacteria, and effective photocatalytic action $[8,9]$.

In this context, global environmental awareness and strict legislation are driving research towards sustainable process implementation. For the fabrication of AgNPs, many biomimetic approaches are being considered. Chemical and physical procedures are among them. They are, however, costly, time-consuming, and hazardous to the environment since their cytotoxicity is strictly dependent on their size and shape [10]. Green synthesis is offered as a straightforward, cost-effective, and ecologically friendly technique of production [11]. Subsequently, the utilization of fruit waste and food waste/by-products as a source of lowering chemicals has grown increasingly appealing due to its potential economic benefits. The valorization of food waste is a progressive direction of resource-saving. Various wastes have been used for the synthesis of AgNPs, such as banana peel [12], papaya peel [13], tea wastes [14], Ambrosia maritima [15], and orange peel [16] have opened a novel method for developing an alternative methodology for the preparation of AgNPs.

Coffee waste is essentially rich in tannins, polyphenols, and caffeine, and it also contains appreciable amounts of carbohydrates, alkaloids, and flavonoids [17]. In 2019/2020, world coffee consumption is estimated at 169.34 million bags, $0.7 \%$ higher than in 2018/2019 as COVID-19 presents a considerable downside risk to global coffee consumption. Currently, demand is estimated to exceed production, projected at 168.86 million bags, by 0.47 million bags in the coffee year 2019/2020 [18, 19]. With this massive production, this type of waste is a significant pollution risk when deposited in landfills across the globe. However, environmentally and renewable phenol-rich agricultural and food waste products mainly contain antioxidants which are considered as a pure source of natural and sustainable additives to functionalize materials for water treatment, biomedical, biorefinery, and energy applications [20].

Thus, coffee waste extract can be used as an excellent reducing and stabilizing agent for the preparation of AgNPs [21]. This green method can be considered a tremendous and environmentally method for the preparation AgNPs, but it has some limitations [22]. For example, yield is limited, the lateral size is high, or using harsh conditions during preparation. More relevant studies based on coffee materials are proposed for the green fabrication of AgNPs with their diverse applications in different fields such as antibacterial activity [23], photocatalytic degradation [24], and supercapacitance investigations [25].

In the present context, the impositions of the CWE in terms of green and sustainable materials to induce the formation of AgNPs matching with circular economy concepts were discussed. Since CWE is used in extract form, without extra chemically reducing agents, this is an easy way to exhibit reproducible, scalable, economic imperative and requires no specialized laboratory equipment or complex apparatuses. CWE was fully characterized and used to degrade phenol compounds with the aid of citric acid and remove the hazardous compound, 2,4-dinitroanilines. Also, the electrochemical investigation was defined, and the antibacterial features against the infected microbes were also evaluated.

\section{Experimental section}

\subsection{Preparation of coffee waste extract (CWE)}

To prepare CWE, the collected coffee waste powder was brought to the laboratory, washed with pure water and filtrated using Whatman filter paper $(0.45 \mu \mathrm{m})$ to obtain the pure powder, which dried at $45{ }^{\circ} \mathrm{C}$ overnight. About $5 \mathrm{~g}$ dry powder was mixed with $50 \mathrm{~mL}$ deionized water and $10 \mathrm{~mL}$ absolute ethanol, then stirring at $80{ }^{\circ} \mathrm{C}$ for $90 \mathrm{~min}$. After that, the solution was filtered again to eliminate visible impurities and then centrifuge at $6000 \mathrm{rpm}$. The pleasant odor extract was stored in a refrigerator at $5{ }^{\circ} \mathrm{C}$ and ready for subsequent experiments.

\subsection{Fabrication of biogenic silver nanoparticles}

To prepare a solution of zero-valent silver nanoparticles (AgNPs), $100 \mathrm{~mL}$ of the prepared extract (CWE) was placed in a $500 \mathrm{~mL}$ conical flask and kept under vigorous magnetic stirring for $5 \mathrm{~min}$ then added $100 \mathrm{~mL}$ dropwise of silver nitrate solution $\left(\mathrm{AgNO}_{3} ; 5 \mathrm{mM}\right.$, molecular weight, $169.87 \mathrm{~g} / \mathrm{mol}$, pure white crystal, ACS reagent $\geq 99.0 \%$ ). In this state, CWE was used as a reducing and stabilizing agent for AgNPs under the effect of temperature $\left(75^{\circ} \mathrm{C}\right)$. After complete addition, it was noted that the color was gradually converted to faint brown, which depicted the formation of AgNPs. It was also remarkable that the faint brown color was turned to a greenish color and fixed after $160 \mathrm{~min}$ of the chemical reaction, affirming all $\mathrm{Ag}$ ions' complete reduction process. The powder of nanoparticle was separated at $8000 \mathrm{rpm}$ for $15 \mathrm{~min}$ and washed with water. The centrifugation and washing process was repeated three times to give the AgNPs. Finally, the obtained powder of AgNPs 
was dried using a freeze dryer (Martin Christ, Germany) at $-60{ }^{\circ} \mathrm{C}$ overnight and then was used for further characterization and application.

\subsection{The main characterization of CWE and CWE capped AgNPs}

HPLC method was used to detect main compounds in CWE, and the experimental was typically conducted as published elsewhere [26, 27].

UV-vis spectrophotometer (ATI Unicam 5625 UV/VIS Vision Software V3.20) was used to screen the as-synthesized AgNPs in the range of 200-800 nm.

ThermoFisher Nicolete IS10 (USA) was used to analyze the chemical functional groups of CWE and CWE cap AgNPs using Fourier transforms infrared (FT-IR) in the range of $4000-500 \mathrm{~cm}^{-1}$ at a resolution of $1 \mathrm{~cm}^{-1}$. $\mathrm{X}$-ray diffraction (XRD; Bruker, B8-advance, X-ray diffractometer) performed at a voltage of $40 \mathrm{kV}$ and a current of $30 \mathrm{~mA}$ with $\mathrm{Cu}$ Ka radiation which used to determine the structure and crystallinity of nanoparticles. Transmission electron microscopy (JEOL, JEM-2100, Japan) was used to examine the particle size, shape, and morphology of the prepared AgNPs. The surface texture and the elemental study was recognized using a scanning electron microscope-energy dispersive X-ray (SEM-EDAX; JEOL JSM-6510/v, Japan).

\subsection{Photocatalytic evaluation study}

Photocatalytic activity of AgNPs was explored through phenol photodegradation using a stock solution from phenol (50 ppm). About $20 \mathrm{~mL}$ of the stock solution was charged into eight different $50 \mathrm{~mL}$ Erlenmeyer flasks. Then different doses of the as-prepared AgNPs (3, 5, 7, 9, and $12 \mathrm{mg}$ ) were added. About $8 \mathrm{~mL}$ citric acid stock solution (ACS reagent, $\geq 99.5 \%$ ) was added to each flask by flow rate process [18]. The mixture in each flask was stirred continuously at room temperature under dark conditions for $40 \mathrm{~min}$ to achieve adsorption-desorption equilibrium before being exposed to a visible light lamp. The handmade visible light photoreactor consists of 2 X 50 Watt visible light in a closed box and light scattered on the top of the reactor. The rate of phenol degradation and the importance of AgNPs in the rapid photocatalytic degradation were revealed through photo spectroscopy analysis. Taking known amount from these stocks in each experiment to identify the reduction behavior of 2,4 dinitroaniline (2,4 DNA). The first three experiments were conducted at room temperature with a constant concentration of citric acid $(8 \mathrm{~mL})$ and various dosage of $\mathrm{AgNPs}(3,5$, and $7 \mathrm{mg}$, respectively) at a continuous $30 \mathrm{~min}$. The three remaining experiments were conducted at room temperature with a constant concentration of AgNPs
(7 mg) and varying the contents of citric acid $(4,6$, and $8 \mathrm{mg}$, respectively) at $40 \mathrm{~min}$.

Double-beam UV-vis detected the remaining concentration, and the degradation percentage $D(\%)$ was calculated using the following relation:

$D(\%)=\left[\left(C_{o}-C_{t}\right) / C_{o}\right] \times 100$

where $C_{\mathrm{o}}$ is the starting concentration of the pollutant before adding the catalyst and $C_{\mathrm{t}}$ is the concentration of the pollutant after degradation at time $t$.

\subsection{Antibacterial activity}

Using a well-agar diffusion process, antibacterial tests were conducted in vitro against many bacterial species, including $E$. coli and $P$. aeruginosa, S. aureus, and B. subtilis. To achieve a uniform shape in a Petri dish, these bacteria were cultivated on nutrient agar. Then, $10 \mathrm{~mL}$ of the as-prepared AgNPs is mounted in a $6 \mathrm{~mm}$ hole in agar and ciprofloxacin discs $(10 \mathrm{~g})$ in the same tray as standard antibiotics. Eventually, all Petri dishes were held to $37{ }^{\circ} \mathrm{C}$ for $24 \mathrm{~h}$ before being tested for the zone of inhibition; this procedure was repeated three times.

\subsection{Electrochemical investigation}

All electrochemical measurements of AgNPs were performed in a $1 \mathrm{M} \mathrm{Na}_{2} \mathrm{SO}_{4}$ solution with a three-electrode cell setup that included a working electrode, a reference $(\mathrm{Ag} / \mathrm{AgCl})$, and a counter electrode ( $\mathrm{Pt}$ coil). A homogeneous slurry of produced AgNPs active nanomaterial (90\%) and poly (vinylidene difluoride) (average $\mathrm{Mw} \sim 534,000$, Sigma Aldrich) (10\%) in a $0.35 \mathrm{~mL}$ N-methyl pyrrolidone (ReagentPlus $囚, 99 \%$, SigmaAldrich) as a solvent was used to make the working electrode. The slurry was poured onto a sheet of stainless steel (current collector) and allowed to dry at $85{ }^{\circ} \mathrm{C}$ after being sonicated for roughly $20 \mathrm{~min}$ at room temperature. Cyclic voltammetry (CV), galvanostatic charge/discharge (GCD), and electrochemical impedance spectroscopy (EIS) were used to examine the properties of the AgNPs as a supercapacitor electrode. GCD and $\mathrm{CV}$ measurements were carried at various current densities ranging from 0.56 to $3.80 \mathrm{~A} \mathrm{~g}^{-1}$ and with a scan rate range from 10 to $100 \mathrm{mV} \mathrm{s}^{-1}$ in between $0-1 \mathrm{~V}$ potential window, respectively. EIS measurements were carried at a steady-state no-load potential with a sinusoidal noise amplitude of $10 \mathrm{mV}$ in the frequency range $10^{5}$ to $0.1 \mathrm{~Hz}$. EC-Lab V11.4 software was used to obtain EIS parameters.

\subsection{Statistical analysis}

The means $\pm \mathrm{SD}$ were performed in this research, and the required figures were represented as three separate tests. An analysis of variance was recognized by using the difference 
Table 1 The test of the active phytochemical components in aqueous extract of coffee waste (CWE)

\begin{tabular}{lll}
\hline Phytochemical test type & Result & Intensity \\
\hline Carbohydrates & + & Low \\
Alkaloids & + & Low \\
Tannins & +++ & High \\
Saponins & + & Low \\
Steroids & - & NA \\
Phenols & +++ & High \\
Proteins and amino acids & + & Low \\
Flavonoids & + & Low \\
Glycosides & + & Low \\
\hline
\end{tabular}

Table 2 Total secondary metabolites content in CWE

\begin{tabular}{lrlcl}
\hline Peak name & R. T & Area & \%Area & Height \\
\hline Gallic acid & 5.628 & 27,502 & 0.11 & 2008 \\
Chlorogenic acid & 18.261 & $2,018,540$ & 40.775 & 130,018 \\
Caffeic acid & 19.793 & 92,014 & 92.14 & $1,348,030$ \\
\hline
\end{tabular}

for each particular test. However, the significance level of 0.05 error $(p<0.05)$ was statistically considered.

\section{Results and discussion}

\subsection{Phytochemical screening}

Before using any substance in any chemical reaction or using it as a substitute for harmful chemical substances, it is necessary to verify its components to determine how it is used and its reaction conditions. Thus, Table 1 summarizes the results of a qualitative phytochemical study of coffee waste extract (CWE). The data revealed active components in the pure extract of CWE with low concentrations of carbohydrates, alkaloids, proteins, amino acids, saponins, and flavonoids. Furthermore, tannins and phenols can be used in high concentrations in chlorogenic acid, gallic acid, and caffeic acid $[17,19,26]$. This proves the waste's effectiveness and potential to preserve the active ingredients in the used coffee powder.

The quantitative study of adequate tannins and caffeic acid responsible for reducing metallic $\mathrm{Ag}^{+}$to $\mathrm{Ag}^{0}[28,29]$ is shown in Table 2. Anything other than that, such content played the dual role of reductant and stabilizing agent for the produced AgNPs attributable to the reducing affinity associated with the electron donation potential, including the hydroxyl groups of phenol compounds [19, 30, 31]. The chemical structure, configuration, and several phenolic hydroxyl groups are primarily responsible for stabilizing and reducing the ions of silver to zero-valent particles. Similarly, findings explored the quantitative and qualitative total tannins and phenols in different extracts using green chemistry to prepare metal nanoparticles [32].

\subsection{HPLC examination}

HPLC technique of pure coffee waste extract included gallic acid, chlorogenic acid, and caffeic acid. Their concentration and chemical structure are shown in Fig. 1 and Table 2. These components can be applied in therapeutic roles such as antimicrobial, antioxidant, anti-inflammatory, loss weight, and blood pressure adjustment [33].

\subsection{UV-vis spectroscopy, PL, and FTIR spectrum of CWE and AgNPs}

The formation of AgNPs was initially confirmed by UV-vis spectroscopy and monitoring the absorption wavelength of CWE before and after using it to prepare AgNPs. As shown in Fig. 2a, the Uv-vis spectra of CWE displayed two distinct peaks at 278 and $321 \mathrm{~nm}$. The synthesized AgNPs via CWE showed a broad peak at $465 \mathrm{~nm}$ (Fig. 2b) due to the surface plasmon resonance (SPR) absorption of AgNPs, which can also be attributed to the accumulated oscillations of free electrons located at the surface of metallic nanoparticulate validated the development of AgNPs [34]. Otherwise, curve at $270 \mathrm{~nm}$ (medium), $354 \mathrm{~nm}$ (weak), and $465 \mathrm{~nm}$ (strong), which described to the quadrupole, out-of-plane dipole, and in-plane dipole plasmon resonance of hexagonal AgNPs [35]. The theoretically calculated bandgap for the prepared AgNPs was $2.67 \mathrm{eV}$.

It has been literaturally and experimentally defined that the synergistic fingerprint region, which confirms this phenomenon by AgNPs, is primarily found in the wavelength range from 400 to $450 \mathrm{~nm}$ [36]. The transformation of silver metal ions $\mathrm{Ag}^{+}$into silver nanoparticles $\mathrm{Ag}^{0}$ through the active biomolecules presented in CWE results in the generation of AgNPs [12]. Thus, the green synthesized AgNPs stabilized via CWE have a plateau at $270 \mathrm{~nm}$ due to the wavelength shifting for CWE from 278 to $270 \mathrm{~nm}$. Irradiating the metal surface with an electron, photon, or laser beam will cause silver to illuminate [37], with confirmed emission peak positions ranging from 300 to $550 \mathrm{~nm}$. Despite the fact that many studies of AgNPs have been reported, we could find few reports on their luminescence study [38, 39].

Figure 2c shows the PL properties of both CWE and CWE stabilized AgNPs. CWE in water exhibits two significant peaks at 376 and $438 \mathrm{~nm}$. The peak of CWE stabilized AgNPs is of lower intensity and shifted to $440 \mathrm{~nm}$. This is probably due to the formation of AgNPs, and it can be concluded that AgNPs under visible light could reduce the rate of electron and hole recombination. The CWE curve's 
Fig. 1 HPLC chromatogram of effective compounds in CWE, including the chemical structures of effective compounds in the CWE
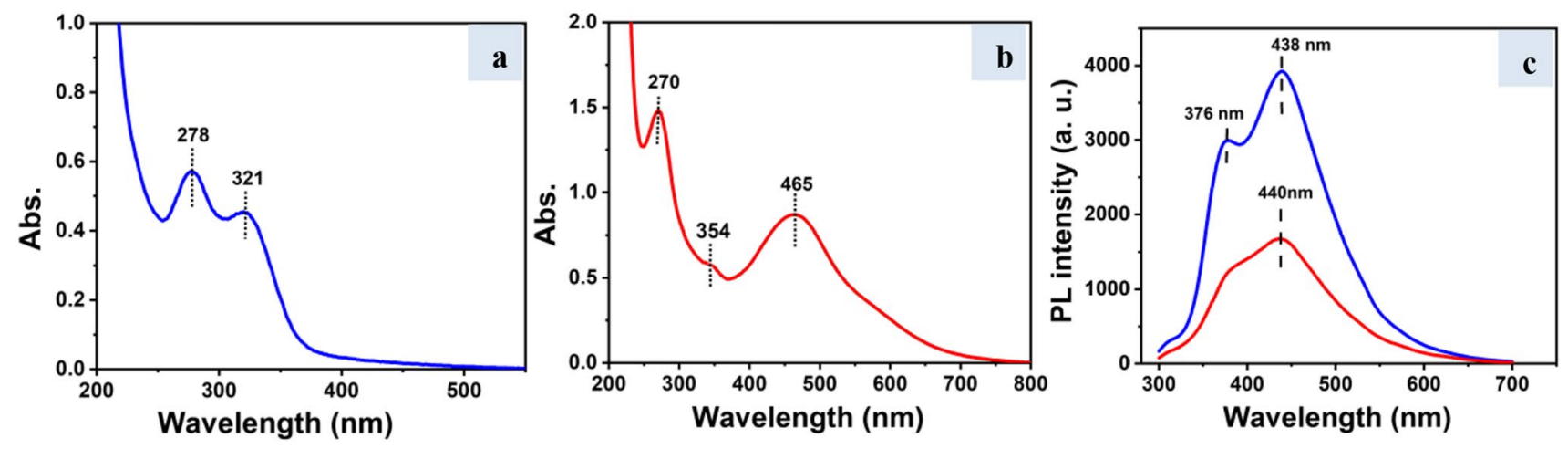

Fig. 2 UV-vis spectral range of a CWE, $\mathbf{b}$ AgNPs by a greenway, and $\mathbf{c}$ photoluminescence emission spectrum of CWE (blue) and CWE stabilized AgNPs (red)

amplitude decreases and becomes broader, indicating a bio-interaction between $\mathrm{CWE}$ and $\mathrm{AgNO}_{3}$ to form the wellstabilized AgNPs.

The PL of Ag or any noble metal excites electrons from occupying d bands in states above the Fermi Level. Consequently, electron/phonon and hole/phonon scattering lose the energy and, eventually, photoluminescence recombination of an electron from such an occupied sp band with a hole [37]. The interband transition is also thought to be direct owing to the minor photon momentum. The emission is caused by direct recombination of conduction band electrons with holes in the $\mathrm{d}$ band scattered to a momentum state much more diminutive than Fermi momentum (KF).

In Fig. 3, the FTIR spectrum showed that $-\mathrm{OH}$ hydroxyl stretching vibration group is dominant because phenols in CWE are related to the broad peak at $3422 \mathrm{~cm}^{-1}$ [40]. Asymmetrical and symmetrical stretching modes resulting from aliphatic alkane groups are also seen at a wavenumber of 2928 and $2857 \mathrm{~cm}^{-1}$ [41], respectively. The absorption peaks that appeared at 1748 and $1649 \mathrm{~cm}^{-1}$ correlate to aliphatic esters and caffeine, respectively, and they coincided with the HPLC results [42].

The intensity of $1500 \mathrm{~cm}^{-1}$ relates to the aromatics' C-C stretching in the ring. Meanwhile, the bands exhibited at $1388-1148 \mathrm{~cm}^{-1}$ are ascribed to the vibration stretching type II-based arabinogalactan carbohydrate peak [43]. On the other side, the $\mathrm{O}-\mathrm{H}$ band that refers to the presence of carboxylic acids appears at $915 \mathrm{~cm}^{-1}$. The $\beta$-type of glycosidic linkages arising from carbohydrates rings is affirmed by the existence of a band between 850 and $805 \mathrm{~cm}^{-1}$, which 


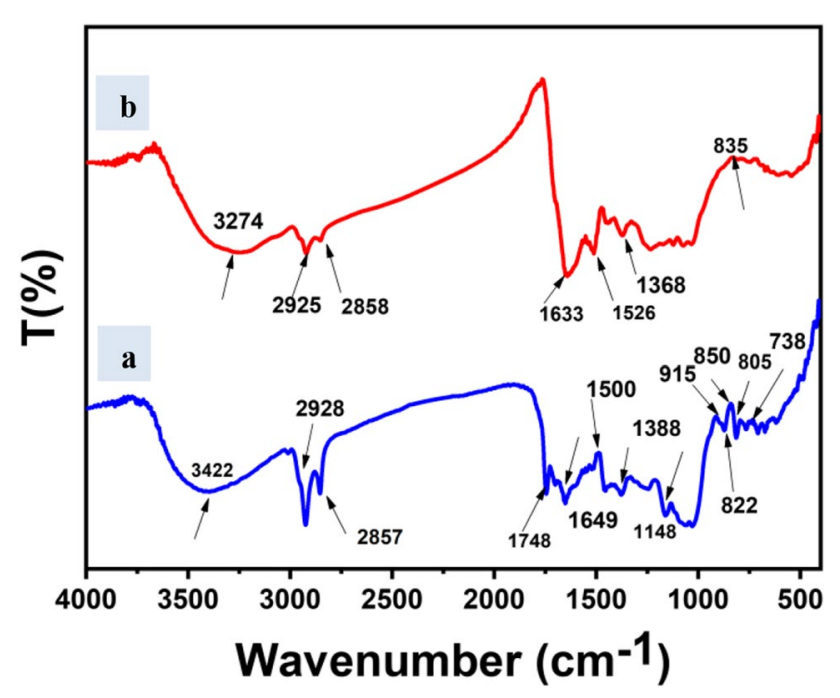

Fig. 3 FTIR spectrums of a CWE and $\mathbf{b}$ AgNPs

depicted the fingerprint of CWE [44]. The peak observed at $738 \mathrm{~cm}^{-1}$ indicated the alkynes group's presence $(-\mathrm{C}=\mathrm{C}-\mathrm{H}$ : $\mathrm{C}-\mathrm{H}$ bending). In the case of AgNPs coated by CWE, the intensity of such peak was lower than that of CWE spectra with broader which validate the formation of AgNPs. The spectra of AgNPs are displayed below the CWE spectra. The spectrum shows the changes in the chemistry of CWE. The spectrum also shows several peak shifts and intensity shape changes of the bands between fingerprint zones of $800-1500 \mathrm{~cm}^{-1}$. This transition of chemical changes is attributed to the reduction of $\mathrm{Ag}^{+}$to $\mathrm{Ag}^{0}$ due to phenolic activity, respectively.

\subsection{XRD and morphological studies}

Figure 4a shows an XRD for the green synthesized AgNPs in the XRD range of $20-80^{\circ}$. It is observed that the synthesized AgNPs has four strong peaks at $2 \theta=37.58^{\circ}, 43.73^{\circ}$, $64.04^{\circ}$ and $76.94^{0}$ corresponding to the planes (111), (200), (220), and (311), respectively) [36, 45]. These obtained peak planes are for face cubic crystal (FCC) structure as matched with (JCPDF Card No-087-0720) which agreed with the literature [46]. These observed peaks are in accordance with those published elsewhere [47], implying the smaller scale, crystalline composition, and high purity of AgNPs produced by the green method.

The interplanar spacing (d spacing) was calculated and compared with JCPDF as shown in Table 3 by using Bragg's Law equation:

$d=\frac{n \lambda}{2 \sin \theta}$

$d=\operatorname{spacing}\left(\mathrm{A}^{0}\right), n=$ order of diffraction $=1, \lambda=1.5418$ the incident wavelength of the XRD, and $\theta=$ the Bragg angle. (D) The average crystalline size of AgNPs is calculated from full-width at half maximum (FWHM) using Debye-Scherer equation:

$D=\frac{K \lambda}{\beta^{1 / 2} \cos \theta}$

as $K=0.9$ (a sharp grain factor) and $\beta=$ the entire width of the XRD peak at half maximum. Thus, it can be observed that the calculated crystal average size is estimated to be $18.9 \mathrm{~nm}$.

Table 3 d-spacing standard and calculated from XRD pattern with the plane

\begin{tabular}{llll}
\hline 2Theta $\left({ }^{0}\right)$ & $d_{\text {standard }}$ & $d_{\text {calculated }}$ & $($ hkl) planes \\
\hline 37.58 & 2.3913 & 2.3932 & $(111)$ \\
43.73 & 2.0682 & 2.0698 & $(200)$ \\
64.73 & 1.4527 & 1.4538 & $(220)$ \\
76.94 & 1.2380 & 1.2391 & $(311)$ \\
\hline
\end{tabular}
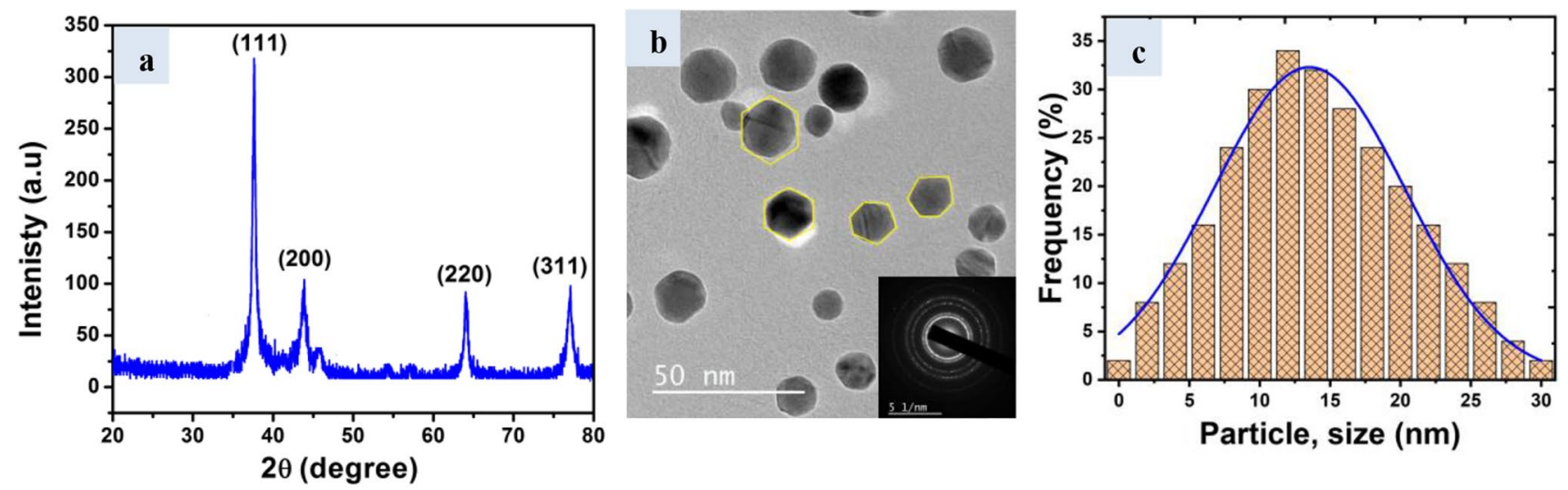

Fig. 4 a XRD pattern, b HR-TEM, (inside SAED), and $\mathbf{c}$ particle size distribution curve of AgNPs 
The morphology and appearance of AgNPs are shown in TEM images (Fig. 4b), which are ascribed to monodispersed spherical and hexagonal shaped AgNPs to some extent (yellow circles) [48]. This unique morphology makes it synergistic in electrochemical supercapacitor (ESS), where ions are absorbed and intercalated onto the surface of the active materials, leading to developed electrochemical performance [49]. Inside Fig. 4b, the selected area diffraction (SAED) of AgNPs in which these bright spots formed four significant planes, which are also in agreement with the graph of XRD. Additionally, the calculated size for the analyzed AgNPs is less than $20 \mathrm{~nm}(13.62 \mathrm{~nm})$ according to the size distribution curve (Fig. 4c), which is typically following the obtained data from XRD.

In Fig. 5, the morphological surface of CWE and AgNPs coated by the steric effect of CWE was assessed using the SEM tool. Remarkably, CWE has a smooth and porous surface [50]; this surface makes it more sparkle as a stabilizer and reducing agent (Fig. 5a). By examining EDAX graphs to outline the elemental contents of each prepared sample, it is revealed that CWE has main elements with their atomic percentage. It can be seen that from the EDAX graph (near SEM) for CWE, there are many elements with their atomic percentages, including C (60.96\%), N (18.99\%), O (19.93\%), and $\mathrm{K}(0.12 \%)$.
On the other hand, the surface structure is entirely different after using stabilizing agent. The surface of CWE has many small particles of AgNPs deposited onto and penetrated the surface of extract, implying that CWE has the potential effect of preparing AgNPs with very small size and is well-stabilized forms (Fig. 5b). Additionally, these hexagonal particles with irregular distribution of AgNPs form sheets or clusters are formed [51]. The high purity of the generated AgNPs affirming the potentially important role of CWE as the percentage of $\mathrm{Ag}$ equal percent 100 is also confirmed by AgNPs EDAX.

\subsection{Degradation of phenol}

The degradation of phenol using citric acid was extended in this context in the presence and absence of the green prepared AgNPs to reveal their effects. The fact that there is almost no difference in absorbance of phenol solution at $\lambda_{\text {max }}=269 \mathrm{~nm}$ in a blank assay without AgNPs indicates a sluggish reduction rate for a phenolic solution. The observed phenol degradation rate after $42 \mathrm{~min}$ is only $8 \%$ (the data are summarized in Fig. 6a and Table 4). When the same experiments were repeated at the presence of different concentrations of AgNPs simultaneously, there was a significant decrease in the absorbance, implying that phenol is reduced significantly by citric acid in the presence of AgNPs. So, it
Fig. 5 SEM of a CW powder with relative EDX and $\mathbf{b}$ SEM of AgNPs and beside EDX analysis
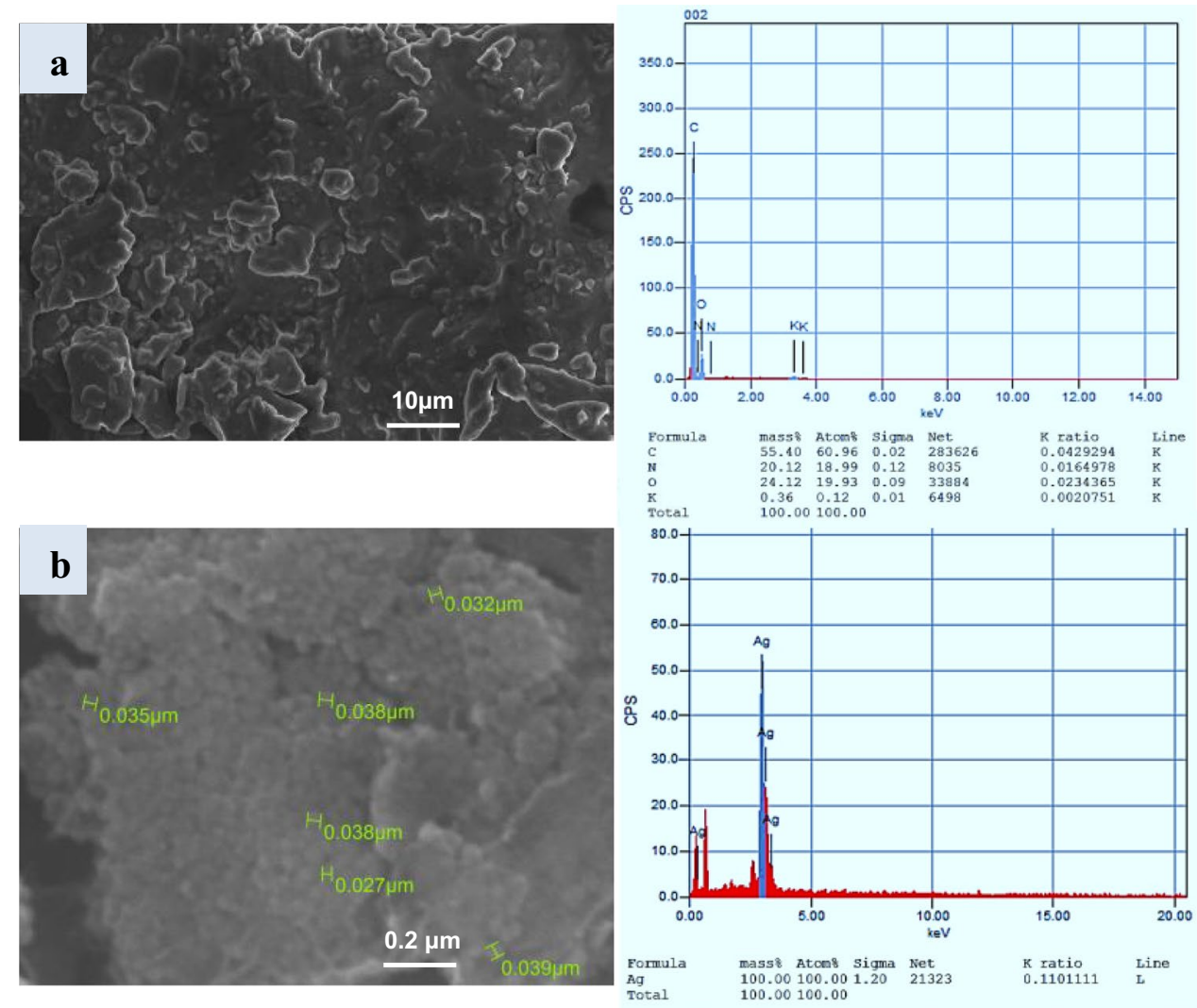

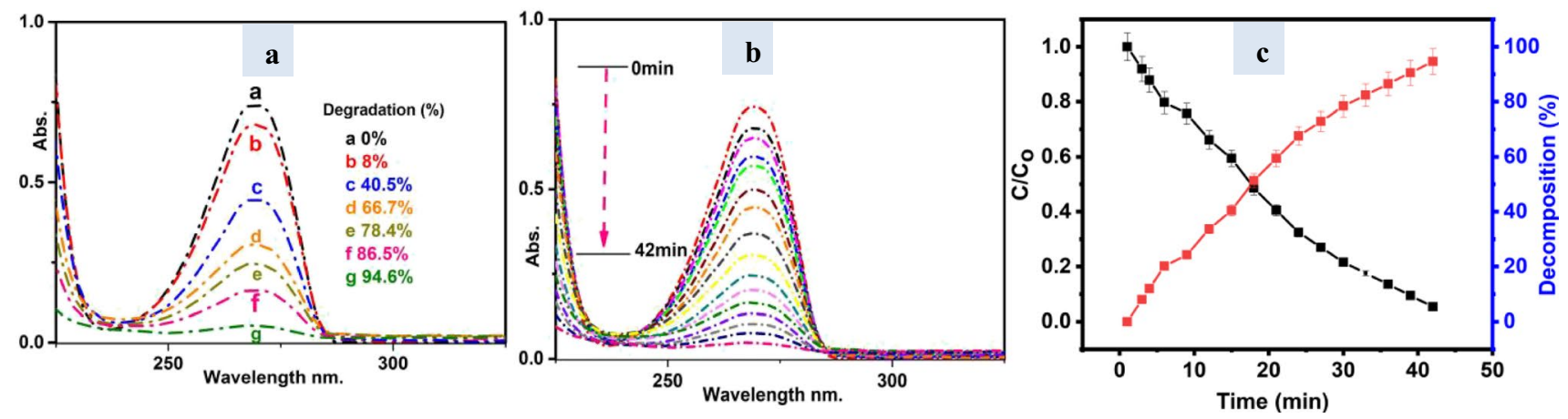

Fig. 6 UV spectra of phenol degradation at different conditions (regarding Table 4) (a), UV spectral degaradtion of phenol [20 mL volume, $8 \mathrm{~mL}$ of citric acid, $12 \mathrm{mg} \mathrm{AgNPs]}$ (b), and the breakdown rate (\%) of AgNPs at optimal dose (12 mg) (c)

can be concluded that AgNPs' surface plasmon resonance (SPR) property allows them to serve as an electron relay center, effectively assisting the transition of electrons from citric acid to phenol and, as a result, increasing the degradation rate [52].

Remarkably, the efficient degradation of phenol has occurred while using AgNPs with a concentration of more than $3 \mathrm{mg}$. Thus, the phenol degradation achieved a maximum in less than 15 min. Therefore, the dosage of AgNPs affects the speed rate at which phenol degrades (Table 4). As shown in Fig. 6b, the maximum rate for phenol degradation is achieved using $12 \mathrm{mg}$ of AgNPs combined with $8 \mathrm{~mL}$ of citric acid $(0.1 \mathrm{M})$. These findings point to AgNPs being synergistic in effectively degrading phenol with citric acid, a unique and novel approach for phenol degradation, and attain $94.6 \%$ (Fig. 6c).

\subsubsection{The mechanism of phenol photodegradation}

The surface area is one of the contributors to enhancing photocatalytic degradation of pollutants [53]. Due to the large surface area of AgNPs $\left(29.3 \mathrm{~m}^{2} \cdot \mathrm{g}^{-1}\right)$, AgNPs have high photocatalytic activity, which is attributed to the fact that increasing the number of surface activation sites available

Table 4 Degradation (\%) of phenol in the absence and presence of AgNPs combined with citric acid (at standard time $42 \mathrm{~min}$ )

\begin{tabular}{lllll}
\hline Sample no & $\begin{array}{l}\text { Volume } \\
\text { of phenol } \\
(\mathrm{mL})\end{array}$ & $\begin{array}{l}\text { Amount of } \\
\text { citric acid } \\
(\mathrm{mL})\end{array}$ & $\begin{array}{l}\text { Amount of } \\
\text { AgNPs }(\mathrm{mg})\end{array}$ & $\begin{array}{l}\text { Degradation } \\
(\%)\end{array}$ \\
\hline A & 20.0 & 0.0 & $12 \mathrm{mg}$ & $0 \%$ \\
B & 20.0 & $8 \mathrm{~mL}$ & 0.0 & $8 \%$ \\
C & 20.0 & $8 \mathrm{~mL}$ & $3 \mathrm{mg}$ & $40.5 \%$ \\
D & 20.0 & $8 \mathrm{~mL}$ & $5 \mathrm{mg}$ & $67.6 \%$ \\
E & 20.0 & $8 \mathrm{~mL}$ & $7 \mathrm{mg}$ & $78.4 \%$ \\
F & 20.0 & $8 \mathrm{~mL}$ & $9 \mathrm{mg}$ & $86.4 \%$ \\
G & 20.0 & $8 \mathrm{~mL}$ & $12 \mathrm{mg}$ & $94.6 \%$ \\
\hline
\end{tabular}

and thus enable the efficient transport of photogenerated electron-hole pairs to the adsorbed species. Besides, AgNPs are penetrated by the visible-light radiation and absorb more photons, consequently producing electron-hole pairs on the surface, leading to direct and indirect oxidation of phenol [54]. On the surface of AgNPs, hydroxyl ions $\left(\mathrm{OH}^{-}\right)$and hydroxyl radicals ${ }^{\bullet} \mathrm{OH}$ are generated when phenol molecules contact water as a result of the indirect oxidation of water molecules. At the same time, ${ }^{\circ} \mathrm{OH}$ can attack the phenyl ring, which immediately opens to produce muconic acid. Following the degradation process, releasing $\mathrm{CO}_{2}$ and $\mathrm{H}_{2} \mathrm{O}$, formic acid and oxalic acid are formed as final mineralization products. The hypochromic effect broadens and shifts the absorption profile from $270 \mathrm{~nm}$ to a bit of $265 \mathrm{~nm}$, indicating the formation of muconic acid [55]. Otherwise, molecular oxygen can scavenge photogenerated conduction band $\left(e_{c b}^{-}\right)$electrons to form superoxide anion radicals $\left(\mathrm{O}_{2}^{-}\right)$. This reaction would provide an additional pathway to degrade phenol molecules. Again water react with $\left(\mathrm{O}_{2}^{-}\right)$to generate $\mathrm{H}_{2} \mathrm{O}_{2}$ and $\mathrm{OH}^{-}$ions. Following the generation scenario, $\mathrm{H}_{2} \mathrm{O}_{2}$ broken by the $\left(e_{c b}^{-}\right)$to ${ }^{\circ} \mathrm{OH}$ (radical) and $\mathrm{OH}^{-}$(ions), which react with $\left(h_{v b}^{+}\right)$to stimulate additional $\bullet \mathrm{OH}$ radicals. As a result, essential $\left(\mathrm{O}_{2}^{-}\right)$and ${ }^{\bullet} \mathrm{OH}$ combined with $\left(h_{v b}^{+}\right)$are highly active species and responsible for repeatedly attacking organic contaminants, and easy photodegradation can attain [56]. Many of the end products of phenol degradation are short-chain organic acids like acetic, formic, and oxalic acid [57]. Nevertheless, some of the most identified intermediates are benzoquinone, along with phenol, 2-chloro-2-nitro-trimethylphosphine oxide, 4-ethylbenzoic acid, succinic acid, and hexadecanoic acid [58].

\subsubsection{Photoreduction of 2,4 dinitroaniline $(2,4$ DNA)}

The effect of catalyst dose Figure 7 (a-c) shows the effect of different doses of AgNPs $(3,5,7 \mathrm{mg})$ on the removal efficiency of 2,4 DNA at a constant time of $30 \mathrm{~min}$. As can be seen from the data, raising the AgNPs catalyst dosage from 
3 to 5 to $7 \mathrm{mg}$ increases the removal performance from 60.7 to $82.72 \%$, respectively. Meanwhile, the removal efficiency of 2,4 DNA is sharply increased to $97.6 \%$ (Fig. 7d) upon increasing the dose of AgNPs to $7 \mathrm{mg}$.

Therefore, it can be concluded that the excitation process improves as the catalytic dosage increases, providing more active sites with significant surface area besides the irradiation through the visible light and the effect of citric acid that can act as an extra reducing agent through flow rate addition. Therefore, it increases the number of hydroxyl radicals, improving the removal efficiency of 2,4 DNA [59]. The strength of the 2,4 DNA absorption peaks at $346 \mathrm{~nm}$ decreased significantly with increasing the irradiation time until it is wholly lost, with no intermediate.

Effect of citric acid concentration Even though citric acid is weaker than other organic acids as formic, mandelic, and acetic acid, it has been widely utilized as a hole scavenger in addition to its chelating agent [60]. Various concentrations from working solution of $0.1 \mathrm{M}$ citric acid; 4,8 , and $12 \mathrm{~mL}$ by flow rate to the total reaction medium. The catalyst and 2,4 DNA are used to demonstrate the effect of citric acid on removing 2,4 DNA, as shown in Fig. $8(\mathrm{a}-\mathrm{c})$. By increasing the concentration of citric acid from 4 to $12 \mathrm{~mL}$, the removal efficiency of 2,4 DNA improves from 63.5 to
$98.4 \%$, depicting the efficiency of scavenging free radicals and antioxidant properties of citric acid, which provides sufficient conditions for rapid reduction of 2,4 DNA. Scheme 1 illustrates the simplistic mechanism for decomposition of 2,4 DNA. Also, the present results encourage comparing our green prepared AgNPs and other AgNPs catalysts that prepared from various wastes in the literature against the selected pollutants as interpreted in Table 5 .

\subsection{Antibacterial activity}

It is well defined that bacterial infections cause the majority of the problems associated with infectious diseases, not only in terms of morbidity but also in medical costs $[65,66]$. The overuse of antibiotics has been related to various problems, including bacterial resistance. Consequently, researchers aim to design a new way to reduce infectious diseases in developing and spreading [67].

Bioinspired AgNPs have been studied against many species of bacterial strains. Ciprofloxacin was selective against all bacteria studied, and the inhibition zone of the tested AgNPs against the microbial species is shown in Table 6 and Fig. 9.

The results revealed that AgNPs are efficient against all utilized bacteria. It is also shown that $P$. aeruginosa is
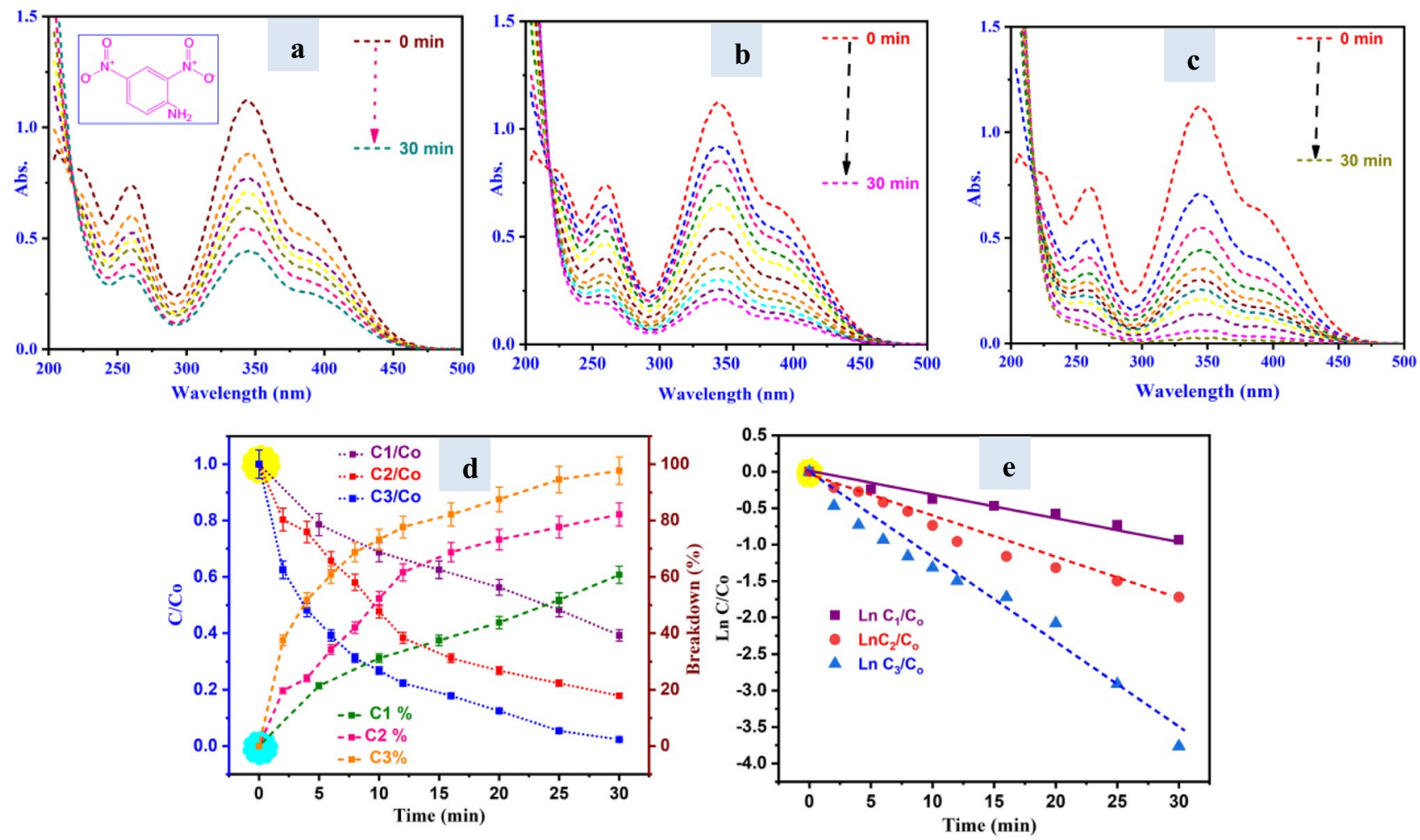

Fig. 7 Photoreduction of 2,4 DNA using (a) $3 \mathrm{mg}$, (b) $5 \mathrm{mg}$, and (c) $7 \mathrm{mg}$, (d) pseudo-first-order kinetic model of 2,4 DNA and their relative breakdown (\%), and (e) fitting curve of kinetics 

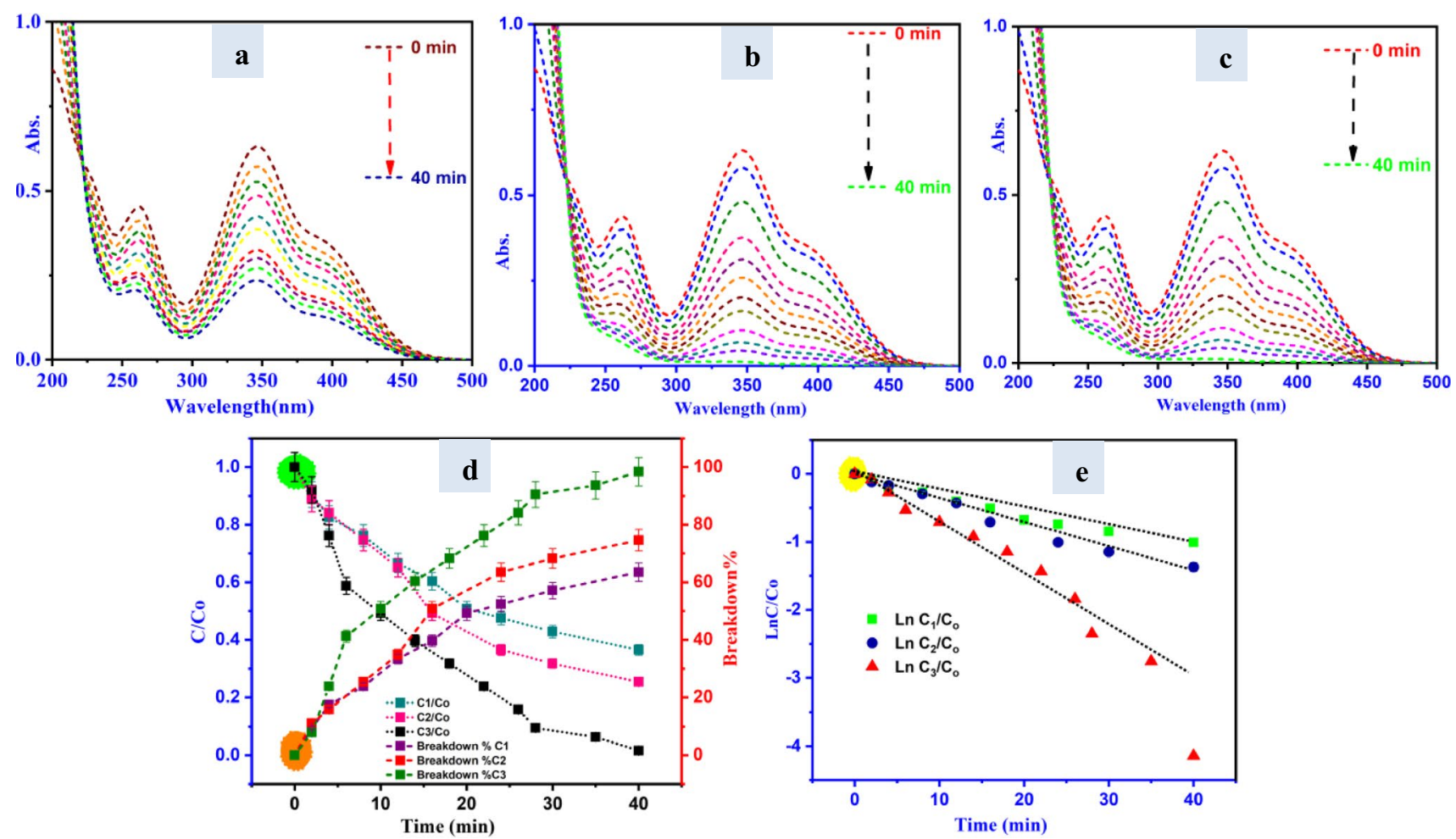

Fig. 8 Photoreduction of 2,4 DNA using citric acid a $4 \mathrm{~mL}, \mathbf{b} 6 \mathrm{~mL}$, and $\mathbf{c} 8 \mathrm{~mL}$, d degradation (\%), and e fitting curve of 2,4 DNA kinetics data

Scheme 1 Photoreduction mechanism of 2,4 DNA

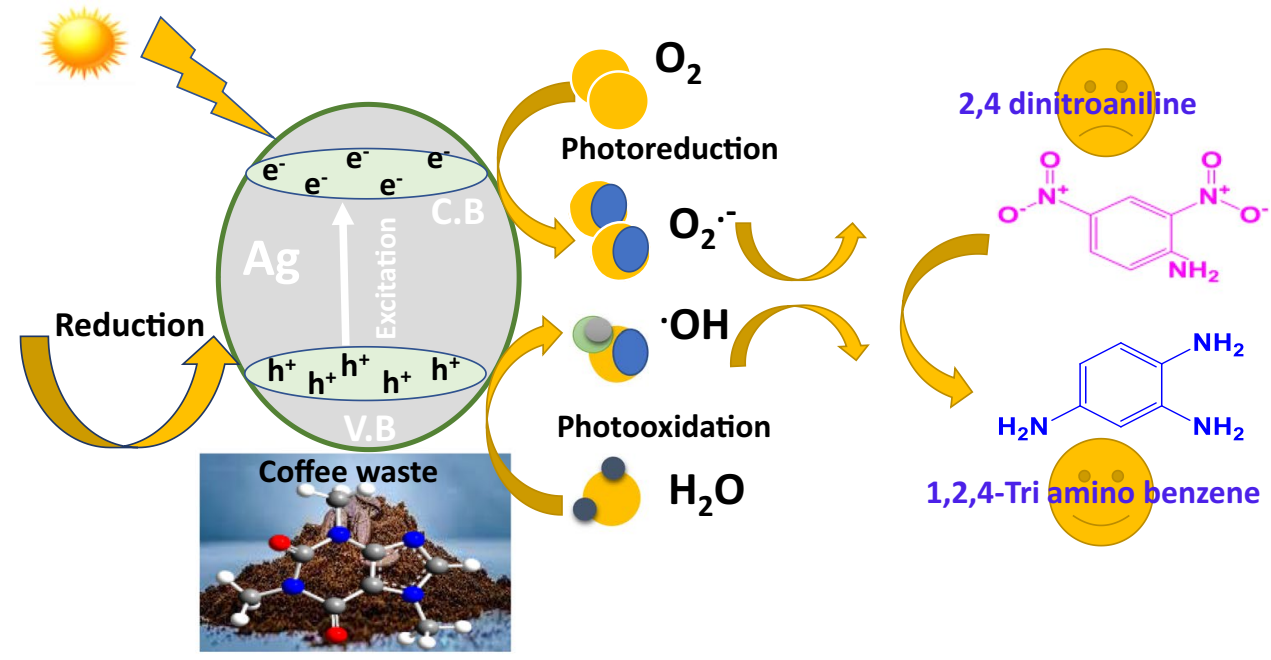

Table 5 Comparing current work and previous studies for AgNPs from wastes in photocatalytic activities against different pollutants

\begin{tabular}{|c|c|c|c|c|c|}
\hline Photocatalyst type & Waste type & Pollutant type & Time (min) & Efficiency $(\%)$ & Ref \\
\hline AgNPs & Bacillus amyloliquefaciens (MSR5) & 4 nitrophenol & 15 & 98 & {$[61]$} \\
\hline $\mathrm{g}-\mathrm{Fe}_{3} \mathrm{O}_{4} / 2 \mathrm{RGO}$ & Averrhoa carambola leaf & Phenol & 150 & $76 \%$ & {$[62]$} \\
\hline $\mathrm{AgNPs}$ & tulsi leaves & 4 nitrophenol & 30 & 100 & {$[63]$} \\
\hline $\mathrm{Ag} / \mathrm{Ag}_{2} \mathrm{O} / \mathrm{P} 25$ & Capsicum annuum L (chili) & 2.4DNA & 60 & 100 & [11] \\
\hline AgNPs & Thymbra spicata/leaves & 4 nitrophenol & 1 & 96 & {$[64]$} \\
\hline \multirow[t]{2}{*}{ AgNPs } & Coffee waste & Phenol & 42 & 94.6 & This work \\
\hline & & 2,4 DNA & 30 & 97.7 & This work \\
\hline
\end{tabular}


the most vulnerable to AgNPs, with a high percentage of inhibition zones of $50 \%$, whereas $B$. subtilis has the lowest rate of inhibition zones, with $40 \%$ vs. $35 \%$ for the typical antibiotic at a concentration of $2 \mathrm{mg} / \mathrm{L}$ of the green synthesized AgNPs. As a result, human pathogenic bacteria were selected for testing the efficacy of AgNPs, and the resulted inhibition zone diameter, as shown in Fig. 9a, follows the order: P. aeruginosa $>$ S. aureus $>$ E. coli $>$ B. subtilis.

Gram-positive bacteria's thick cell wall with peptidoglycan layers $(80 \mathrm{~nm}$ ) enables AgNPs to penetrate more directly with the outer bacterial membrane than gramnegative bacteria's lipopolysaccharides (1-3 $\mathrm{mm}$ in thick), which protect the cell surface [68]. The membrane of gram-positive bacteria ruptures and kills them due to the difference in bacterial cell wall structure $[69,70]$. AgNPs' antibacterial efficacy is attributable to their small size and high surface-to-volume ratio, allowing these nanoparticles to interact directly with bacterial membranes with minimal size (less than $25 \mathrm{~nm}$ ). The cytoplasmic membrane is broken by direct contact of AgNPs with the bacterial cell wall. Various cytoplasmic biomolecules, such as proteins, carbohydrates, and amino acids, appear in the cytoplasm exposure after treatment with AgNPs. As reported in the antibacterial mechanistic is inferred that AgNPs promoted large cell wall pits that inactivate the respiratory chain due to membrane permeability [71]. Another common explanation for the mechanism is that the bacterial cell membrane's electric potential is altered when AgNPs bind to carboxyl and phosphate groups, causing ion and molecule massive leakage and consequently cell death [72]. Also, the deterioration in bacteria's cell wall is based on the interaction of AgNPs with DNA, enzymes, and proteins involved in the metabolic pathway of bacteria, causing significant metabolism to stop and death [73]. In our system, AgNPs are associated with triggering the activation of reactive oxygen species (ROS) abundance, leading to oxidative stress, lipid peroxidation, protein oxidation, and DNA damage [74]. Figure $9 b$ is a simple diagram representing the possible pathway of AgNPs while tackling the cell wall of bacterial species.
Table 6 The inhibition zone by AgNPs and ciprofloxacin as standard antibiotics for grampositive and Gram-negative bacteria

Fig. 9 Antibacterial activity of AgNPs and ciprofloxacin standard antibiotics nominated bacteria with an inhibition zone of $\mathbf{a}$ $P$. aeruginosa, $\mathbf{b} S$. aureus, $\mathbf{c} E$. coli, $\mathbf{d} B$. subtilis, and e possible pathway of AgNPs antibacterial effectiveness during attacking the bacteria

\begin{tabular}{lllll}
\hline Material used & $\begin{array}{l}\text { Pseudomonas } \\
\text { aeruginosa }\end{array}$ & $\begin{array}{l}\text { Staphylococcus } \\
\text { aureus }\end{array}$ & Escherichia coli & Bacillus subtilis \\
\hline Ciprofloxacin & $11.2 \pm 0.1$ & $9.5 \pm 0.1$ & $6.4 \pm 0.1$ & $5.1 \pm 0.1$ \\
Fabricated AgNPs & $24.3 \pm 0.2$ & $20.2 \pm 0.3$ & $11.4 \pm 0.3$ & $10.2 \pm 0.3$ \\
\hline
\end{tabular}
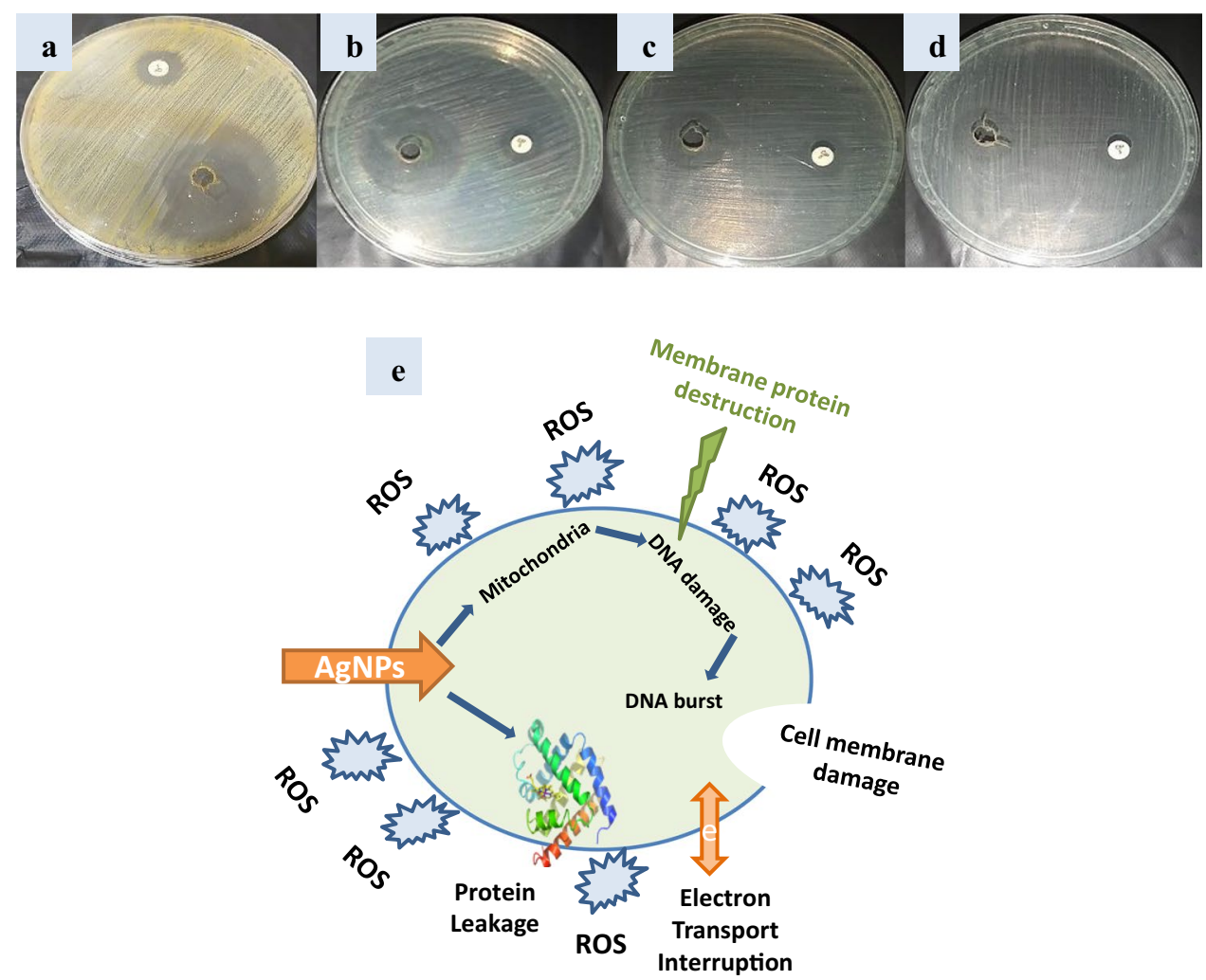


\subsection{Electrochemical capacitance}

As known, an essential aspect in estimating a material's electrochemical capacitance is the galvanostatic charge/discharge (GCD) calculation. The GCD curves for synthesized AgNPs electrodes of supercapacitors with current densities ranging from 0.56 to $3.80 \mathrm{Ag}^{-1}$ are shown in Fig. 10a. As shown in Fig. 10b, the Nyquist plot of the synthesized AgNPs electrode demonstrates a medium semicircle with acceptable Rct (781) in the high-frequency zone and ESR of 1.2 in the low-frequency zone. As shown in Fig. 10c, the specific capacitance of the synthesized AgNPs electrode was high, with an estimated value of $280 \mathrm{Fg}^{-1}$ at a current density of $0.56 \mathrm{Ag}^{-1}$, which is better than other references using a high molar ratio of aqueous electrolyte (Table 7). Electrochemical impedance spectroscopy (EIS) measurements were employed to assess the device's electrochemical behavior.
In assessing supercapacitor electrodes, long cycle life is a necessary requirement. After 1000 cycles, the charge-discharge rate and capacitance of the synthesized AgNPs electrode showed minimal degradation, with $94.8 \%$ capacitance retention.

\section{Conclusions}

Given the promising efficiency and eco-benign nature of biogenic synthesis, the waste extract (coffee waste extract (CWE)) was successfully used to fabricate AgNPs under ambient conditions within a short reaction time and one-step procedure. There is a quick and environmentally friendly method for preparing silver nanoparticles meaning the whole procedure was conducted in distilled water with no use of hazardous reagents or organic solvents. CWE and
Fig. 10 GCD of synthesized AgNPs at a specific current from 0.56 to $3.80 \mathrm{Ag}^{-1}$ (a), Nyquist plots of synthesized AgNPs developed with $1 \mathrm{M}$ $\mathrm{Na}_{2} \mathrm{SO}_{4}(\mathbf{b})$, the calculated $C_{\text {sp }}$ and $\eta \%$ at a specific current from 0.56 to $3.80 \mathrm{Ag}^{-1}$ for synthesized AgNPs (c), and the capacitance retention for synthesized AgNPs (d)
Table 7 Some previous work and electrochemical performance for nanostructured composites electrodes
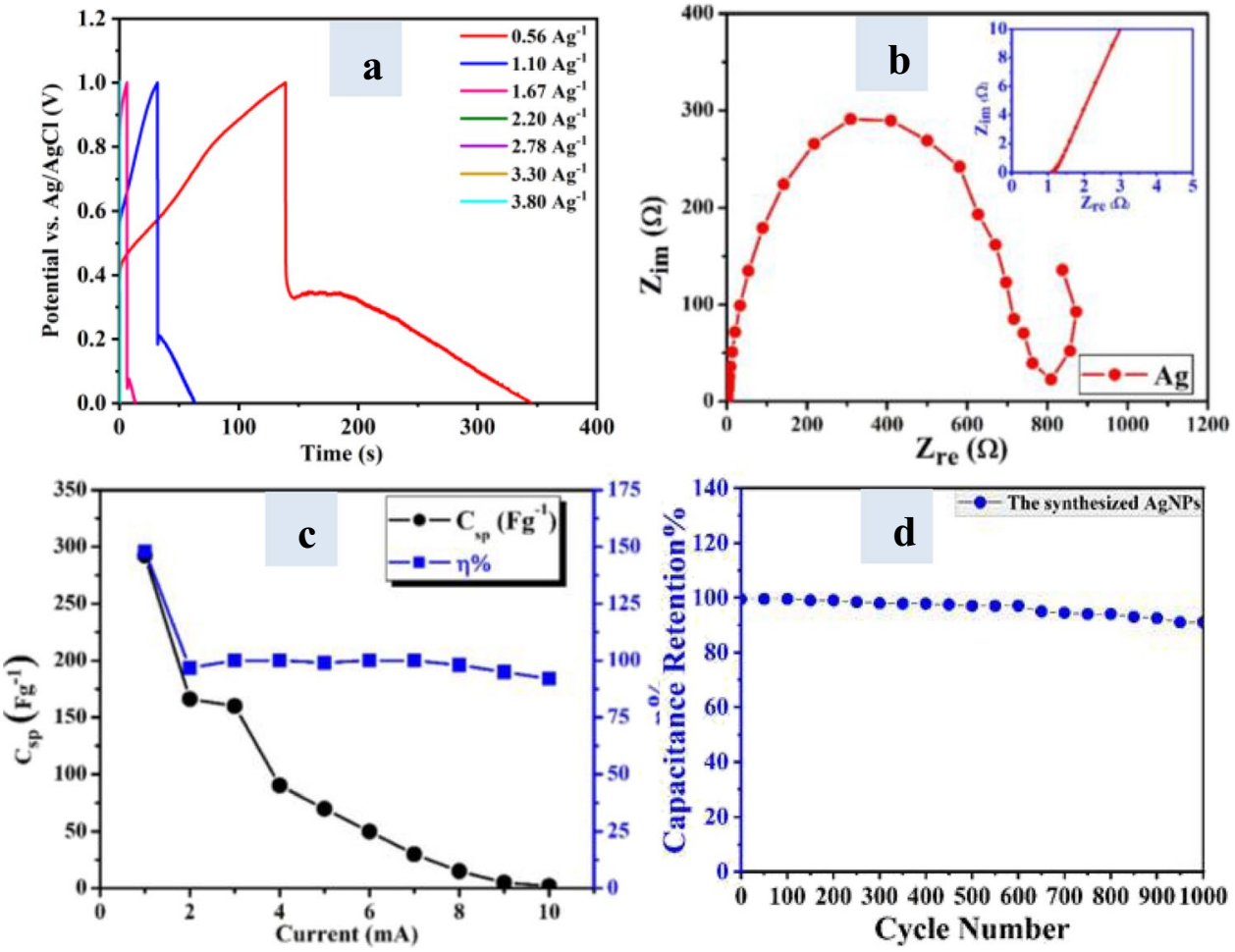

Cycle Number

\begin{tabular}{lllllll}
\hline Active material & Type & Electrolyte & $\begin{array}{l}\text { Specific capaci- } \\
\text { tance }\left(\mathrm{Fg}^{-1}\right)\end{array}$ & $\begin{array}{l}\text { Energy } \\
\text { density }(\mathrm{Wh} \\
\left.\mathrm{kg}^{-1}\right)\end{array}$ & $\begin{array}{l}\text { Power } \\
\text { density }(\mathrm{W} \\
\left.\mathrm{kg}^{-1}\right)\end{array}$ & Ref \\
\hline PANi/rGA/AgNPs & Cell & $6 \mathrm{M} \mathrm{NaOH}$ & 365.14 & $64-116$ & $1550-7944$ & {$[75]$} \\
$\mathrm{Ag} / \mathrm{RGO} / \mathrm{CF}$ & Electrode & $0.5 \mathrm{M} \mathrm{NaOH}$ & 426 & 34.6 & 125 & {$[76]$} \\
GNs/AgNPs & Electrode & $4 \mathrm{M} \mathrm{KOH}$ & 528 & - & - & {$[49]$} \\
GNS/AgNPs/PPY & Electrode & $1 \mathrm{M} \mathrm{KCl}$ & 450 & 81 & $10,000.13$ & {$[77]$} \\
RGO.Ag/Co & Electrode & $3 \mathrm{M} \mathrm{KOH}$ & $450.88-567.04$ & $57.83-69.16$ & 200 & {$[78]$} \\
AgNPs & Electrode & $1 \mathrm{M} \mathrm{Na}_{2} \mathrm{SO}_{4}$ & 280 & 37 & 646.6 & This work \\
\hline
\end{tabular}


CWE coated AgNPs were fully characterized by UV-vis, FTIR, XRD, and TEM SEM-EDAX techniques. HPLC depicted that CWE has many natural compounds available to reduce silver ions to nanoparticles, and hydroxyl-bearing compounds cap these nanoparticles and prevent them from agglomeration. The biogenic route furnished the hexagonal AgNPs in the nano range of less than $50 \mathrm{~nm}$ and crystalline. The biogenic AgNPs showed promising photocatalysts and an antibacterial agent for many infected microbes. The benign synthesis of AgNPs was further used as a catalyst for accelerating the removal of phenols in the presence of citric acid. It was depicted that AgNPs displayed higher catalytic activity and antibacterial features. Moreover, AgNPs can be conserved as photoreduction agents due to their efficient photoreduction of 2,4 dinitroaniline (2,4 DNA) with a short time. At $0.56 \mathrm{~A} \mathrm{~g}^{-1}$, AgNPs exhibited $280 \mathrm{~F} \mathrm{~g}^{-1}$ and showed cyclic stability $94.8 \%$ capacitance retention. As a result, the synthesis of AgNPs using CWE (useless wastes) is dependable, efficient, stable, scalable, reproducible, and appropriate for various areas.

Acknowledgements We thank Mahmoud Maher from the Institute of Engineering and Technology, Egypt, for his technical support in electrochemical measurements.

Author contribution All authors have shared writing, revising, and preparing the manuscript.

Data availability Not Applicable.

\section{Declarations}

Conflict of interest The authors declare no competing interests.

\section{References}

1. Rathi BS, Kumar PS, Show P-L (2021) A review on effective removal of emerging contaminants from aquatic systems: current trends and scope for further research. J Hazard Mat 409124413

2. Shoueir K, El-Sheshtawy H, Misbah M, El-Hosainy H, El-Mehasseb I, El-Kemary M (2018) Fenton-like nanocatalyst for photodegradation of methylene blue under visible light activated by hybrid green DNSA@ chitosan@ $\mathrm{MnFe}_{2} \mathrm{O}_{4}$. Carbohyd Polym 197:17-28

3. El-Sheshtawy HS, Shoueir KR, El-Kemary M (2020) Activated $\mathrm{H}_{2} \mathrm{O}_{2}$ on $\mathrm{Ag} / \mathrm{SiO}_{2}-\mathrm{SrWO} 4$ surface for enhanced dark and visiblelight removal of methylene blue and p-nitrophenol, J Alloys Comp 842155848

4. Seid L, Lakhdari D, Berkani M, Belgherbi O, Chouder D, Vasseghian Y, Lakhdari N (2022) High-efficiency electrochemical degradation of phenol in aqueous solutions using Ni-PPy and Cu-PPy composite materials. J Hazard Mat 423126986

5. Pandian AMK, Rajasimman M, Rajamohan N, Varjani S, Karthikeyan C (2021) Anaerobic mixed consortium (AMC) mediated enhanced biosynthesis of silver nano particles (AgNPs) and its application for the removal of phenol. J Hazard Mat 416 125717
6. Tong C, Guo Y, Liu W (2010) Simultaneous determination of five nitroaniline and dinitroaniline isomers in wastewaters by solidphase extraction and high-performance liquid chromatography with ultraviolet detection. Chemosphere 81(3):430-435

7. Soto KM, Quezada-Cervantes CT, Hernández-Iturriaga M, LunaBárcenas G, Vazquez-Duhalt R, Mendoza S (2019) Fruit peels waste for the green synthesis of silver nanoparticles with antimicrobial activity against foodborne pathogens. LWT 103:293-300

8. Korkmaz N, Ceylan Y, Hamid A, Karadăg A, Bülbül AS, Aftab MN, Çevik O, Şen F (2020) Biogenic silver nanoparticles synthesized via Mimusops elengi fruit extract, a study on antibiofilm, antibacterial, and anticancer activities. J Drug Deliv Sci Technol 5910186

9. El-Desouky N, Shoueir KR, El-Mehasseb I, El-Kemary M (2021) Bio-inspired green manufacturing of plasmonic silver nanoparticles/Degussa using banana waste peduncles: photocatalytic, antimicrobial, and cytotoxicity evaluatio. J Mat Res Technol 10:671-686

10. Aboelmaati MG, Gaber SAA, Soliman WE, Elkhatib WF, Abdelhameed AM, Sahyon HA, El-Kemary M (2021) Biogenic and biocompatible silver nanoparticles for an apoptotic anti-ovarian activity and as polydopamine-functionalized antibiotic carrier for an augmented antibiofilm activity. Colloids Surf B: Biointerf 111935

11. El-Shabasy R, Yosri N, El-Seedi H, Shoueir K, El-Kemary M (2019) A green synthetic approach using chili plant supported Ag/ $\mathrm{Ag}_{2} \mathrm{O} @ \mathrm{P} 25$ heterostructure with enhanced photocatalytic properties under solar irradiation. Optik 192162943

12. Ibrahim HM (2015) Green synthesis and characterization of silver nanoparticles using banana peel extract and their antimicrobial activity against representative microorganisms. J Radiat Res Appl Sci 8(3):265-275

13. Balavijayalakshmi J, Ramalakshmi V (2017) Carica papaya peel mediated synthesis of silver nanoparticles and its antibacterial activity against human pathogens. J Appl Res Technol 15(5):413-422

14. Qing W, Chen K, Wang Y, Liu X, Lu M (2017) Green synthesis of silver nanoparticles by waste tea extract and degradation of organic dye in the absence and presence of $\mathrm{H} 2 \mathrm{O} 2$. Appl Surf Sci 423:1019-1024

15. Han J, Zhang L, Zhao B, Qin L, Wang Y, Xing F (2019) The $\mathrm{N}$-doped activated carbon derived from sugarcane bagasse for $\mathrm{CO}_{2}$ adsorption. Ind Crops Prod 128:290-297

16. de Barros CHN, Cruz GCF, Mayrink W, Tasic L (2018) Bio-based synthesis of silver nanoparticles from orange waste: effects of distinct biomolecule coatings on size, morphology, and antimicrobial activity. Nanotechnol Sci Appl 11:1

17. Manasa V, Padmanabhan A, Appaiah KA (2021) Utilization of coffee pulp waste for rapid recovery of pectin and polyphenols for sustainable material recycle. Waste Manage 120:762-771

18. Islam MT Synthesis of advanced functional nanomaterials for sustainable water treatment technologies, The University of Texas at El Paso2019

19. Wong-Paz JE, Guyot S, Aguilar-Zárate P, Muñiz-Márquez DB, Contreras-Esquivel JC, Aguilar CN (2021) Structural characterization of native and oxidized procyanidins (condensed tannins) from coffee pulp (Coffea arabica) using phloroglucinolysis and thioglycolysis-HPLC-ESI-MS. Food Chemistry 340127830

20. Zhu H, Luo W, Ciesielski PN, Fang Z, Zhu J, Henriksson G, Himmel ME, Hu L (2016) Wood-derived materials for green electronics, biological devices, and energy applications. Chem Rev 116(16):9305-9374

21. Mangindaan D, Lin G-Y, Kuo C-J, Chien H-W (2020) Biosynthesis of silver nanoparticles as catalyst by spent coffee ground/ recycled poly (ethylene terephthalate) composites. Food Bioprod Process 121:193-201 
22. Uzair B, Liaqat A, Iqbal H, Menaa B, Razzaq A,Thiripuranathar G, Fatima Rana N, Menaa F (2020) Green and cost-effective synthesis of metallic nanoparticles by algae: safe methods for translational medicine. Bioengineering 7(4) 129

23. Wang M, Zhang W, Zheng X, Zhu P (2017) Antibacterial and catalytic activities of biosynthesized silver nanoparticles prepared by using an aqueous extract of green coffee bean as a reducing agent. RSC Adv 7(20):12144-12149

24. Metz K, Sanders S, Pender J, Dix M, Hinds D, Quinn S, Ward A, Duffy P, Cullen R, Colavita P (2015) ACS Sustainable Chem. Eng 3:1610-1617

25. Tang L, Duan F, Chen M (2017) Green synthesis of silver nanoparticles embedded in polyaniline nanofibers via vitamin C for supercapacitor applications. J Mater Sci: Mater Electron 28(11):7769-7777

26. Angeloni S, Navarini L, Khamitova G, Maggi F, Sagratini G, Vittori S, Caprioli G (2020) A new analytical method for the simultaneous quantification of isoflavones and lignans in 25 green coffee samples by HPLC-MS/MS. Food chemistry 325126924

27. NzekoueFK, Angeloni S, Navarini L, Angeloni C, Freschi M, Hrelia S, Vitali LA, Sagratini G, Vittori S, Caprioli G (2020) Coffee silverskin extracts: quantification of 30 bioactive compounds by a new HPLC-MS/MS method and evaluation of their antioxidant and antibacterial activities. Food Res Int 133109128

28. Panzella L, Cerruti P, Aprea P, Paolillo R, Pellegrino G, Moccia F, Condorelli GG, Vollaro A, Ambrogi V, Catania MR (2020) Silver nanoparticles on hydrolyzed spent coffee grounds (HSCG) for green antibacterial devices. J Clean Prod 268122352

29. Abbasian R, Jafarizadeh-Malmiri H (2020) Green approach in gold, silver and selenium nanoparticles using coffee bean extract. Open Agriculture 5(1):761-767

30. Saygi KO, Usta C (2021) Rosa canina waste seed extract-mediated synthesis of silver nanoparticles and the evaluation of its antimutagenic action in Salmonella typhimurium. Mat Chem Phys 266124537

31. Saygi KO, Cacan E (2021) Antioxidant and cytotoxic activities of silver nanoparticles synthesized using Tilia cordata flowers extract. Mat Today Commun 27102316

32. Rónavári A, Igaz N, Adamecz DI, Szerencsés B, Molnar C, Kónya Z, Pfeiffer I, Kiricsi M (2021) Green silver and gold nanoparticles: biological synthesis approaches and potentials for biomedical applications. Molecules 26(4):844

33. Okur I, Soyler B, Sezer P, Oztop MH, Alpas H (2021) Improving the recovery of phenolic compounds from spent coffee grounds (SCG) by environmentally friendly extraction techniques. Molecules 26(3):613

34. Rolim WR, Pelegrino MT, de Araújo Lima B, Ferraz LS, Costa FN, Bernardes JS, Rodigues T, Brocchi M, Seabra AB (2019) Green tea extract mediated biogenic synthesis of silver nanoparticles: characterization, cytotoxicity evaluation and antibacterial activity. Appl Surf Sci 463:66-74

35. Jia H, Xu W, An J, Li D, Zhao B (2006) A simple method to synthesize triangular silver nanoparticles by light irradiation. Spectrochim Acta Part A Mol Biomol Spectrosc 64(4):956-960

36. Dhand V, Soumya L, Bharadwaj S, Chakra S, Bhatt D, Sreedhar B (2016) Green synthesis of silver nanoparticles using Coffea arabica seed extract and its antibacterial activity. Mater Sci Eng, C 58:36-43

37. Fayaz M, Tiwary C, Kalaichelvan P, Venkatesan R (2010) Blue orange light emission from biogenic synthesized silver nanoparticles using Trichoderma viride. Colloids Surf, B 75(1):175-178

38. Zahran M, El-Kemary M, Khalifa S, El-Seedi H (2018) Spectral studies of silver nanoparticles biosynthesized by Origanum majorana. Green Processing and Synthesis 7(2):100-105

39. El-Aswar EI, Zahran MM, El-Kemary M (2019) Optical and electrochemical studies of silver nanoparticles biosynthesized by
Haplophyllum tuberculatum extract and their antibacterial activity in wastewater treatment. Mat Res Exp 6(10):105016

40. Capek P, Paulovičová E, Matulová M, Mislovičová D, Navarini L, Suggi-Liverani F (2014) Coffea arabica instant coffee-chemical view and immunomodulating properties. Carbohyd Polym 103:418-426

41. Suresh G, Gunasekar PH, Kokila D, Prabhu D, Dinesh D, Ravichandran N, Ramesh B, Koodalingam A, Siva GV (2014) Green synthesis of silver nanoparticles using Delphinium denudatum root extract exhibits antibacterial and mosquito larvicidal activities. Spectrochim Acta Part A Mol Biomol Spectrosc 127:61-66

42. Wang N, Lim L-T (2012) Fourier transform infrared and physicochemical analyses of roasted coffee. J Agric Food Chem 60(21):5446-5453

43. Masek A, Latos-Brozio M, Kałużna-Czaplińska J, Rosiak A, Chrzescijanska E (2020) Antioxidant properties of green coffee extract. Forests 11(5):557

44. Naganathan KK, Faizal ANM, Zaini MAA, Ali A (2021) Adsorptive removal of Bisphenol a from aqueous solution using activated carbon from coffee residue. Mat Today: Proc

45. Francis S, Joseph S, Koshy EP, Mathew B (2018) Microwave assisted green synthesis of silver nanoparticles using leaf extract of elephantopus scaber and its environmental and biological applications. Artif Cells Nanomed Biotechnol 46(4):795-804

46. Vijilvani C, Bindhu M, Frincy F, AlSalhi MS, Sabitha S, Saravanakumar K, Devanesan S, Umadevi M, Aljaafreh MJ, Atif M (200) Antimicrobial and catalytic activities of biosynthesized gold, silver and palladium nanoparticles from Solanum nigurum leaves. J Photochem Photobiol B: Biol 202111713

47. Göl F, Aygün A, Seyrankaya A, Gür T, Yenikaya C, Şen F (2020) Green synthesis and characterization of Camellia sinensis mediated silver nanoparticles for antibacterial ceramic applications. Mat Chem Phys 250123037

48. Banerjee A, Das D, Andler R, Bandopadhyay R (2021) Green synthesis of silver nanoparticles using exopolysaccharides produced by Bacillus anthracis PFAB2 and its biocidal property. J Polym Environ 1-9

49. Khamlich S, Khamliche T, Dhlamini M, Khenfouch M, Mothudi B, Maaza M (2017) Rapid microwave-assisted growth of silver nanoparticles on 3D graphene networks for supercapacitor application. J Colloid Interface Sci 493:130-137

50. Deotale SM, Dutta S, Moses J, Anandharamakrishnan C (2020) Stability of instant coffee foam by nanobubbles using spray-freeze drying technique. Food Bioprocess Technol 13(11):1866-1877

51. Küp FO, Çoşkunçay S, Duman F (2020) Biosynthesis of silver nanoparticles using leaf extract of Aesculus hippocastanum (horse chestnut): evaluation of their antibacterial, antioxidant and drug release system activities. Mat Sci Eng: C 107110207

52. Li W, Wen Z, Tian S, Shan L, Xiong Y (2018) Citric acid-assisted hydrothermal synthesis of a self-modified $\mathrm{Bi}_{2} \mathrm{SiO}_{5} / \mathrm{Bi}_{12} \mathrm{SiO}_{20}$ heterojunction for efficient photocatalytic degradation of aqueous pollutants. Catal Sci Technol 8(4):1051-1061

53. Gai H, Wang H, Liu L, Feng B, Xiao M, Tang Y, Qu X, Song H, Huang T (2021) Potassium and iodide codoped mesoporous titanium dioxide for enhancing photocatalytic degradation of phenolic compounds. Chem Phys Lett 767138367

54. Scott T, Zhao H, Deng W, Feng X, Li Y (2019) Photocatalytic degradation of phenol in water under simulated sunlight by an ultrathin $\mathrm{MgO}$ coated $\mathrm{Ag} / \mathrm{TiO}_{2}$ nanocomposite. Chemosphere 216:1-8

55. Gilea D, Radu T, Muresanu M, Carja G (2018) Plasmonic photocatalysts based on silver nanoparticles-layered double hydroxides for efficient removal of toxic compounds using solar light. Appl Surf Sci 444:407-413

56. Rahmani AR, Poormohammadi A, Zamani F, Birgani YT, Jorfi S, Gholizadeh S, Mohammadi MJ, Almasi H (2018) Activated 
persulfate by chelating agent $\mathrm{Fe} /$ complex for in situ degradation of phenol: intermediate identification and optimization study. Res Chem Intermed 44(9):5501-5519

57. Guérette C, Lemoine P, Ramirez P, Segura PA (2021) Determination of short-chain carboxylic acids and non-targeted analysis of water samples treated by wet air oxidation using gas chromatography-mass spectrometry. J Chromatogr A (2021) 462352

58. Lou S, Chen Q, Wang W, Wang Y, Zhou S (2021) Templateassisted synthesis of $\mathrm{Ag} / \mathrm{AgCl}$ hollow microcubes and their composition-dependent photocatalytic activity for the degradation of phenol. RSC Adv 11(42):26311-26318

59. Malakootian M, Gharaghani MA, Dehdarirad A, Khatami M, Ahmadian M, Heidari MR, Mahdizadeh H (2019) ZnO nanoparticles immobilized on the surface of stones to study the removal efficiency of 4-nitroaniline by the hybrid advanced oxidation process $\left(\mathrm{UV} / \mathrm{ZnO} / \mathrm{O}_{3}\right)$. J Mol Struct 1176:766-776

60. Sarwar N, Humayoun UB, Kumar M, Zaidi SFA, YooJH, Ali N, Jeong DI, Lee JH, Yoon(2021) Citric acid mediated green synthesis of copper nanoparticles using cinnamon bark extract and its multifaceted applications. J Clean Prod 292125974

61. Samuel MS, Jose S, Selvarajan E, Mathimani T, Pugazhendhi A (2020) Biosynthesized silver nanoparticles using Bacillus amyloliquefaciens; application for cytotoxicity effect on A549 cell line and photocatalytic degradation of p-nitrophenol. J Photochem Photobiol B: Biol 202111642

62. Padhi DK, Panigrahi TK, Parida K, Singh S, Mishra P (2017) Green synthesis of $\mathrm{Fe}_{3} \mathrm{O}_{4} / \mathrm{RGO}$ nanocomposite with enhanced photocatalytic performance for $\mathrm{Cr}$ (VI) reduction, phenol degradation, and antibacterial activity. ACS Sustainab Chemi Eng 5(11):10551-10562

63. Singh J, Mehta A, Rawat M, Basu S (2018) Green synthesis of silver nanoparticles using sun dried tulsi leaves and its catalytic application for 4-nitrophenol reduction. J Environ Chem Eng 6(1):1468-1474

64. Veisi H, Azizi S, Mohammadi P (2018) Green synthesis of the silver nanoparticles mediated by Thymbra spicata extract and its application as a heterogeneous and recyclable nanocatalyst for catalytic reduction of a variety of dyes in water. J Clean Prod 170:1536-1543

65. Salama A, Diab MA, Abou-Zeid RE, Aljohani HA, Shoueir KR (2018) Crosslinked alginate/silica/zinc oxide nanocomposite: a sustainable material with antibacterial properties, Composites. Communications 7:7-11

66. Shoueir K, Wassel AR, Ahmed M, El-Naggar ME (2020) Encapsulation of extremely stable polyaniline onto Bio-MOF: photoactivated antimicrobial and depletion of ciprofloxacin from aqueous solutions. J Photochem Photobiol A: Chem 400112703

67. Qais FA, Ahmad I, Altaf M, Manoharadas S, Al-Rayes BF, Abuhasil MSA, Almaroai YA (2021) Biofabricated silver nanoparticles exhibit broad-spectrum antibiofilm and antiquorum sensing activity against gram-negative bacteria. RSC Adv 11(23):13700-13710

68. Santos RS, Figueiredo C, Azevedo NF, Braeckmans K, De Smedt SC (2018) Nanomaterials and molecular transporters to overcome the bacterial envelope barrier: towards advanced delivery of antibiotics. Adv Drug Deliv Rev 136:28-48

69. Huang M, Zhuang H, Zhao J, Wang J, Yan W, Zhang J (2020) Differences in cellular damage induced by dielectric barrier discharge plasma between Salmonella Typhimurium and Staphylococcus aureus. Bioelectrochemistry 132107445

70. Tavares TD, Antunes JC, Padrão J, Ribeiro AI, Zille A, Amorim MTP, Ferreira F, Felgueiras HP (2020) Activity of specialized biomolecules against gram-positive and gram-negative bacteria. Antibiotics 9(6):314

71. Reddy N, Li H, Hou T, Bethu M, Ren Z, Zhang Z (2021) Phytosynthesis of silver nanoparticles using Perilla frutescens leaf extract: characterization and evaluation of antibacterial, antioxidant, and anticancer activities. Int J Nanomed 16:15

72. Kanniah P, Chelliah P, Thangapandi JR, Gnanadhas G, Mahendran V, Robert M (2021) Green synthesis of antibacterial and cytotoxic silver nanoparticles by Piper nigrum seed extract and development of antibacterial silver based chitosan nanocomposite. Int J Biol Macromol 189:18-33

73. Husain S, Verma SK, Azam M, Sardar M, Haq Q, Fatma T (2021) Antibacterial efficacy of facile cyanobacterial silver nanoparticles inferred by antioxidant mechanism. Mat Sci Eng: C 122111888

74. Al Jahdaly BA, Al-Radadi NS, Eldin GM, Almahri A, Ahmed M, Shoueir K, Janowska I (2021) Selenium nanoparticles synthesized using an eco-friendly method: dye decolorization from aqueous solutions, cell viability, antioxidant, and antibacterial effectiveness. J Mat Res Technol 11:85-97

75. Pattananuwat $P$, Thammasaroj $P$, Nuanwat $\mathrm{W}$, Qin J, Potiyaraj P (2018) One-pot method to synthesis polyaniline wrapped graphene aerogel/silver nanoparticle composites for solid-state supercapacitor devices. Mater Lett 217:104-108

76. Karami Z, Youssefi M, Raeissi K, Zhiani M (2021) An efficient textile-based electrode utilizing silver nanoparticles/reduced graphene oxide/cotton fabric composite for high-performance wearable supercapacitors. Electrochimica Acta 368:137647

77. Kalambate PK, Dar RA, Karna SP, Srivastava AK (2015) High performance supercapacitor based on graphene-silver nanoparticles-polypyrrole nanocomposite coated on glassy carbon electrode. J Power Sources 276:262-270

78. Selim AM, Zahran MB, Khalifa W, El-Mahallawi IS (2021) Facile synthesis of hybrid electrode materials based on RGO. Ag/Co for an efficient symmetric supercapacitor. J Electroanalyt Chem 886 115114

Publisher's Note Springer Nature remains neutral with regard to jurisdictional claims in published maps and institutional affiliations. 